\title{
Comparative safety and efficacy of antithrombotics in the management of venous thromboembolism after knee or hip replacement surgery: focus on rivaroxaban
}

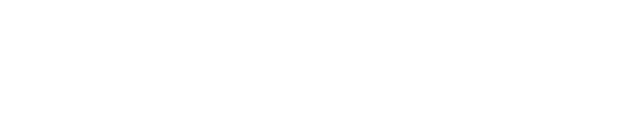

\section{Louis M Kwong}

Department of Orthopedic Surgery, Harbor-UCLA Medical Center, Torrance, CA, USA
Correspondence: Louis M Kwong Department of Orthopedic Surgery, Harbor-UCLA Medical Center, 1000 W Carson Street, Box 422, Torrance, CA 90509, USA

$\mathrm{Tel}+\mathrm{I} 3102222716$

Email lkwong@dhs.lacounty.gov
Abstract: Routine thromboprophylaxis represents the current standard of care in the management of patients following total hip or knee replacement. Legacy agents used to address the issue of risk of venous thromboembolism present barriers to use, either by the need for monitoring and dose adjustment (warfarin) or the need for injection (low molecular weight heparins and fondaparinux), or pose a risk of upper gastrointestinal bleeding (acetylsalicylic acid and all antithrombotic agents). The introduction of new pharmacologic agents in recent years has sought to address the issues of not only efficacy, but also safety, ease of use, and patient compliance. New orally administered agents, ie, apixaban, dabigatran, and rivaroxaban, have demonstrated various degrees of efficacy over enoxaparin while preserving safety. Indirect comparisons of the relative efficacies of apixaban, dabigatran, and rivaroxaban have shown rivaroxaban to be more efficacious than dabigatran and apixaban in reducing symptomatic and total venous thromboembolism following total hip or knee replacement surgery. A pooled analysis of the four RECORD (Regulation of Coagulation in Orthopedic Surgery to Prevent deep vein thrombosis and pulmonary embolism) trials (two in total hip replacement and two in total knee replacement) demonstrated rivaroxaban to be the first and only antithrombotic agent ever to demonstrate superiority in reducing symptomatic venous thromboembolism and all-cause mortality compared with another antithrombotic agent (enoxaparin). New oral antithrombotic agents have demonstrated efficacy in prophylaxis against venous thromboembolism following total hip or knee replacement surgery while preserving safety, with increased ease of administration of thromboprophylaxis for both the patient and the physician, which may contribute to improved compliance.

Keywords: thromboprophylaxis, venous thromboembolism, rivaroxaban, total hip replacement, total knee replacement

\section{Introduction}

Physiologic responses of the body to total hip or knee replacement surgery put patients at high risk for venous thromboembolism. Routine thromboprophylaxis represents the current standard of care in the management of patients following total hip or knee replacement. ${ }^{1}$ Controversy exists as to the optimum prophylactic regimen, and no single strategy has been identified that is best for all patients. The introduction of new pharmacologic agents in recent years has sought to address the issues of not only efficacy, but also safety, ease of use, and patient compliance. Of primary concern to orthopedic surgeons is the issue of bleeding, leading some surgeons to take a non- 
evidenced-based approach to thromboprophylaxis in order to increase the margin of safety in terms of a reduction in hemorrhagic complications and potential infection risk. ${ }^{2-4}$

\section{Pharmacologic antithrombotic overview}

Warfarin has been used as a thromboprophylactic agent following arthroplasty for over four decades. The vitamin $\mathrm{K}$-dependent factors (II, VII, IX, X) in the coagulation cascade are targeted by warfarin, bringing about a dosedependent systemic anticoagulation. The use of doseadjusted warfarin has been validated as an effective strategy in reducing the risk of venous thromboembolism, but its use is associated with a number of challenges. An INR value of at least 2.0 has been advocated by a number of organizations as a target for effective thromboprophylaxis following total hip or knee replacement. ${ }^{5,6}$ This requires phlebotomy for anticoagulation monitoring in order to adjust the warfarin dosage to achieve the target INR as a balance between efficacy and safety. Further, significant variation exists in terms of individual response to warfarin, with some patients appearing to be very warfarin-sensitive, while others are relatively warfarin-resistant. Warfarin also has many potential food and drug interactions, so if warfarin use is instituted for prophylaxis against venous thromboembolism, it is critical to obtain a very careful drug inventory from the patient, because potentially serious drug interactions are largely preventable. Absent is a warfarin service to manage anticoagulation, the labor-intensive nature of this strategy serves as a disincentive to the orthopedic surgeon to manage venous thromboembolism prophylaxis by these means.

Low molecular weight heparins have been used since the 1980s and are a class of pharmacologic agents in widespread use for prophylaxis against venous thromboembolism following total hip or knee arthroplasty. Enoxaparin, dalteparin, and nadroparin are representative low molecular weight heparins, and achieve their antithrombotic effect by targeting factor Xa and, to a lesser degree, factor IIa, in the coagulation cascade. Pivotal trials involving the various low molecular weight heparins have generally demonstrated approximately 50\% superior efficacy compared with warfarin, with comparable safety. ${ }^{7-9}$ Enoxaparin is approved for use as prophylaxis against venous thromboembolism following total hip or knee replacement surgery. Dalteparin has an indication for use following total hip replacement only, and nadroparin is not approved for use in the United States. These agents require subcutaneous injection, so the cooperation of a knowledgeable and compliant patient who is instructed in self-administration, or the use of a family member or nursing personnel, is required in order to employ this strategy successfully. Until recently, no antithrombotic regimen had been found to be superior in efficacy to the North American regimen of enoxaparin $30 \mathrm{mg}$ subcutaneously every 12 hours. Since its introduction into the orthopedic community as a thromboprophylactic agent, it has been anecdotally reported that there is a tendency for patients on enoxaparin to have increased drainage from the surgical site. While efforts to quantify this drainage have been unsuccessful, this is of concern to many orthopedic surgeons because of the potential increase in infection risk. A recently published literature review demonstrates parity in the division between those studies that report an increase in infection in association with hemorrhagic complications following joint arthroplasty with the use of pharmacologic prophylaxis, and those that demonstrate no association. ${ }^{10}$ Because hospital lengths of stay have gradually declined, an increasingly large proportion of venous thromboembolism events occur post discharge, beyond the realm of surveillance by health care providers. Patient compliance with continued subcutaneous low molecular weight heparin injection post discharge is a concern for many physicians.

Fondaparinux is a selective inhibitor of factor $\mathrm{Xa}$ and is also administered once daily by subcutaneous injection. It acts by reversibly binding antithrombin, bringing about a conformational change that leads to irreversible binding with factor Xa. While a meta-analysis of the fondaparinux pivotal trials demonstrates superiority to enoxaparin in reducing the risk of venous thromboembolism following total hip replacement, total knee replacement, and hip fracture, ${ }^{11}$ this agent has seen less widespread use compared with the low molecular weight heparins. It is currently the only antithrombotic agent with an indication for use in thromboprophylaxis following hip fracture. Like low molecular weight heparins, the need for subcutaneous self-injection is an area of concern with regard to compliance, for both short-term and extendedduration prophylaxis in the post-discharge setting.

Acetylsalicylic acid (aspirin) is not an antithrombotic agent in that it has no effects on the coagulation cascade. It is a nonselective inhibitor of cyclo-oxygenase- 1 and cyclooxygenase-2. The activity of acetylsalicylic acid leads to inhibition of arachidonic acid conversion to cyclo-oxygenase-2, leading to disruption of platelet aggregation, thereby indirectly reducing the risk of thrombosis. ${ }^{12}$ While there is ample level 1 scientific evidence to support the efficacy of virtually all antithrombotic agents in decreasing the risk of venous thromboembolism, no level 1 scientific evidence exists 
for acetylsalicylic acid with regard to venous thrombosis. A significant body of clinical data in support of the efficacy of acetylsalicylic acid in prophylaxis against deep vein thrombosis comes from the arthroplasty series at the University of Pennsylvania, ${ }^{13}$ where Lotke advocates the use of acetylsalicylic acid $325 \mathrm{mg}$ orally twice daily for 6 weeks as an effective strategy for reducing the risk of deep vein thrombosis. ${ }^{14}$ Use of acetylsalicylic acid in deep vein thrombosis prophylaxis is employed by approximately $16 \%-18 \%$ of orthopedic surgeons in the United States following total hip or knee replacement. However, many surgeons use lowdose (81 mg) acetylsalicylic acid once daily, although routine use of this dose is not supported in the literature by advocates of acetylsalicylic acid. While acetylsalicylic acid $325 \mathrm{mg}$ orally twice daily is a simple and inexpensive strategy, additional risks posed by this approach center on the risk of upper gastrointestinal bleeding. In the United Kingdom, in an effort to reduce the risk of upper gastrointestinal bleeding, which is increased by up to 3.2-fold with acetylsalicylic acid regimens ranging from 150-300 mg orally twice daily following hip and knee replacement, ranitidine at a dosage of $300 \mathrm{mg}$ once daily has been advocated and is utilized in order to mitigate the hemorrhagic risks associated with acetylsalicylic acid. ${ }^{15}$ The Pulmonary Embolism Prevention Trial is often cited as supportive evidence of the effectiveness of acetylsalicylic acid in reducing the risk of venous thromboembolism. While this study demonstrated that patients randomized to the acetylsalicylic acid group had fewer venous thromboembolism events compared with placebo in patients following hip fracture, the same was not found in patients following hip and knee replacement. ${ }^{16}$ Further, patients randomized to the acetylsalicylic acid arm were allowed concurrent use of additional thromboprophylactic measures, including mechanical prophylaxis and even low molecular weight heparin administration, so a study that truly isolates the effects of acetylsalicylic acid is still needed.

\section{New pharmacologic antithrombotic agents}

Dabigatran is a direct thrombin inhibitor and selectively targets factor IIa. Its use has been studied in prophylaxis against venous thromboembolism following total hip replacement or total knee arthroplasty. It has been developed as an oral agent to be administered once daily. Pivotal trials have demonstrated dabigatran to be noninferior to enoxaparin $40 \mathrm{mg}$ once a day in the prevention of symptomatic venous thromboembolism and all-cause mortality following total hip arthroplasty. In pivotal trials involving total knee arthroplasty, dabigatran was found to be superior to the European regimen of enoxaparin $40 \mathrm{mg}$ once a day but to be inferior to the regimen of enoxaparin $30 \mathrm{mg}$ every 12 hours used in the United States. ${ }^{17-19}$ Safety was found to be comparable with that of enoxaparin. ${ }^{17}$ It has been demonstrated that use of dabigatran in patients with renal insufficiency may result in accumulation. As a result, dose adjustments may be required in patients with moderate renal insufficiency. Dabigatran is contraindicated in patients with severe renal insufficiency. It has been approved for use in the European Union and Canada, but is not approved for use in venous thromboembolism prophylaxis in the United States.

Apixaban is a direct inhibitor of factor Xa. This is an oral agent designed to be administered twice daily. In pivotal trials against enoxaparin, apixaban failed to demonstrate noninferiority against the regimen of enoxaparin used in the United States, but was found to be superior to the European regimen of enoxaparin for both total hip replacement and total knee arthroplasty, with a lower rate of major and clinically relevant nonmajor bleeding. ${ }^{20-22}$ It is not approved for use as prophylaxis against venous thromboembolism in the United States.

Rivaroxaban is the first drug in the class of direct inhibitors of factor Xa that has reached the market. ${ }^{23}$ It is designed to be administered orally at a fixed dose of $10 \mathrm{mg}$ once a day. No monitoring or dose adjustment is required when used for prophylaxis against venous thromboembolism. One third of the drug is excreted renally, and two thirds is cleared via the hepatobiliary route. Rivaroxaban is contraindicated in patients with a creatinine clearance $<15 \mathrm{~mL}$ per minute. The half-life in normal individuals is approximately 9 hours. The safety and efficacy of rivaroxaban at a fixed dose of $10 \mathrm{mg}$ was compared against enoxaparin in four pivotal trials in the RECORD (Regulation of Coagulation in Orthopedic Surgery to Prevent deep vein thrombosis and pulmonary embolism) program. RECORD1 and RECORD2 included patients following total hip replacement, while RECORD3 and RECORD4 included patients following total knee replacement. In RECORD1, 5 weeks of rivaroxaban was compared against 5 weeks of enoxaparin. In RECORD2, 5 weeks of rivaroxaban was compared with 2 weeks of enoxaparin followed by 2 weeks of placebo to assess the benefits of extending the duration of drug administration from 2 weeks to 5 weeks. In both RECORD3 and RECORD4, 12 days of rivaroxaban was compared with 12 days of enoxaparin. At over 12,500 patients, RECORD is the largest orthopedic development program ever conducted. All four RECORD trials demonstrated superiority in reducing total venous thromboembolism compared with enoxaparin. ${ }^{24-27}$ Additionally, in the RECORD4 study of total knee arthroplasty, 
rivaroxaban was found to be the first and only thromboprophylactic agent to demonstrate superiority over the regimen of enoxaparin $30 \mathrm{mg}$ every 12 hours used in the United States for reducing total venous thromboembolism. Safety was found to be comparable between the two drugs in all four RECORD trials with regard to bleeding, hepatic, and cardiac events, with good tolerability. With regard to long-term safety outcomes, a pooled analysis of safety data revealed that the incidence of any adverse events was similar between the rivaroxaban group (70.6\%) and the enoxaparin group (72.53\%). ${ }^{28}$ Rivaroxaban was approved by the United States Food and Drug Administration on July 1, 2011 for use in the prophylaxis against deep vein thrombosis which may lead to pulmonary embolism in patients following total hip or knee replacement surgery.

\section{Comparative efficacy and safety}

No study has directly compared the safety and efficacy of any of the new oral antithrombotic agents (rivaroxaban, dabigatran, and apixaban) against all legacy thromboprophylactic strategies (low molecular weight heparin, warfarin, acetylsalicylic acid). Similarly, no direct comparisons between any of the new antithrombotic agents to evaluate their comparative safety and efficacy have been conducted. What is known based on level 1 scientific evidence in randomized controlled trials is that the low molecular weight heparins as a group (enoxaparin and dalteparin) are superior in efficacy to warfarin, fondaparinux is superior to enoxaparin, rivaroxaban is superior to enoxaparin, and dabigatran and apixaban show noninferiority to enoxaparin. It is not possible to compare safety data from trial to trial because there is no standardized definition of bleeding that has been used uniformly in all randomized controlled trials. Differences in reported major bleeding rates among pivotal trials for various antithrombotic agents are driven to a large extent by the actual definitions of bleeding, which were much stricter and limited in scope in the RECORD trials, driven partially by the regimens utilized and partially by the properties of the agents themselves. It is more useful to assess the risks of bleeding relative to the comparator rather than focusing on the absolute major bleeding rates of an agent in isolation.

Published studies have made indirect comparisons, via enoxaparin, of the relative efficacies of rivaroxaban, dabigatran, and apixaban. ${ }^{29-31}$ These indirect comparisons have suggested that rivaroxaban may be more efficacious than dabigatran and apixaban in reducing symptomatic and total venous thromboembolism following total hip or knee replacement surgery.
Neither warfarin, low molecular weight heparins, fondaparinux, dabigatran, apixaban, nor acetylsalicylic acid have ever been shown to achieve a statistically significant reduction in symptomatic venous thromboembolism and mortality over any other thromboprophylactic strategy. However, a pooled analysis of the four RECORD trials, two in total hip replacement and two in total knee replacement, demonstrated rivaroxaban to be superior in reducing the composite of symptomatic venous thromboembolism and all-cause mortality compared with enoxaparin. ${ }^{32,33}$ This superiority over another antithrombotic has not been demonstrated previously or established in meta-analysis or indirect comparisons of various thromboprophylactic agents since then. ${ }^{29,30}$ The composite of symptomatic venous thromboembolism and all-cause mortality was reduced by over $50 \%$ with the use of rivaroxaban compared with enoxaparin (Figure 1). This superiority was achieved without a statistically significant increase in major bleeding, minor bleeding, or clinically relevant nonmajor bleeding, although the composite of major and clinically relevant nonmajor bleeding was found to be higher on rivaroxaban than on enoxaparin and this is supported by other analyses. ${ }^{30,34}$

\section{Discussion}

Direct and indirect data from randomized controlled trials regarding venous thromboembolism prophylaxis following major orthopedic surgery demonstrate improved efficacy of rivaroxaban compared with dabigatran and apixaban, and superiority compared with enoxaparin. Orthopedic surgery practice in the area of venous thromboembolism prophylaxis has been guided by concerns over bleeding with modern agents as a result of the perception that patients are being exposed to bleeding risks with more efficacious agents without a demonstrated impact on symptomatic venous thromboembolism events or mortality. ${ }^{35}$ Results from the pooled analysis of over 12,000 patients involved in the RECORD trials dispel those notions now, with the demonstrated impact of rivaroxaban in reducing the composite of symptomatic venous thromboembolism events and all-cause mortality compared with enoxaparin.

\section{Conclusion}

The availability of new oral antithrombotic agents has increased the ease of administration of thromboprophylaxis for both the patient and the physician, which may contribute to improved compliance. The demonstrated superior efficacy of rivaroxaban holds the promise of a reduction in 


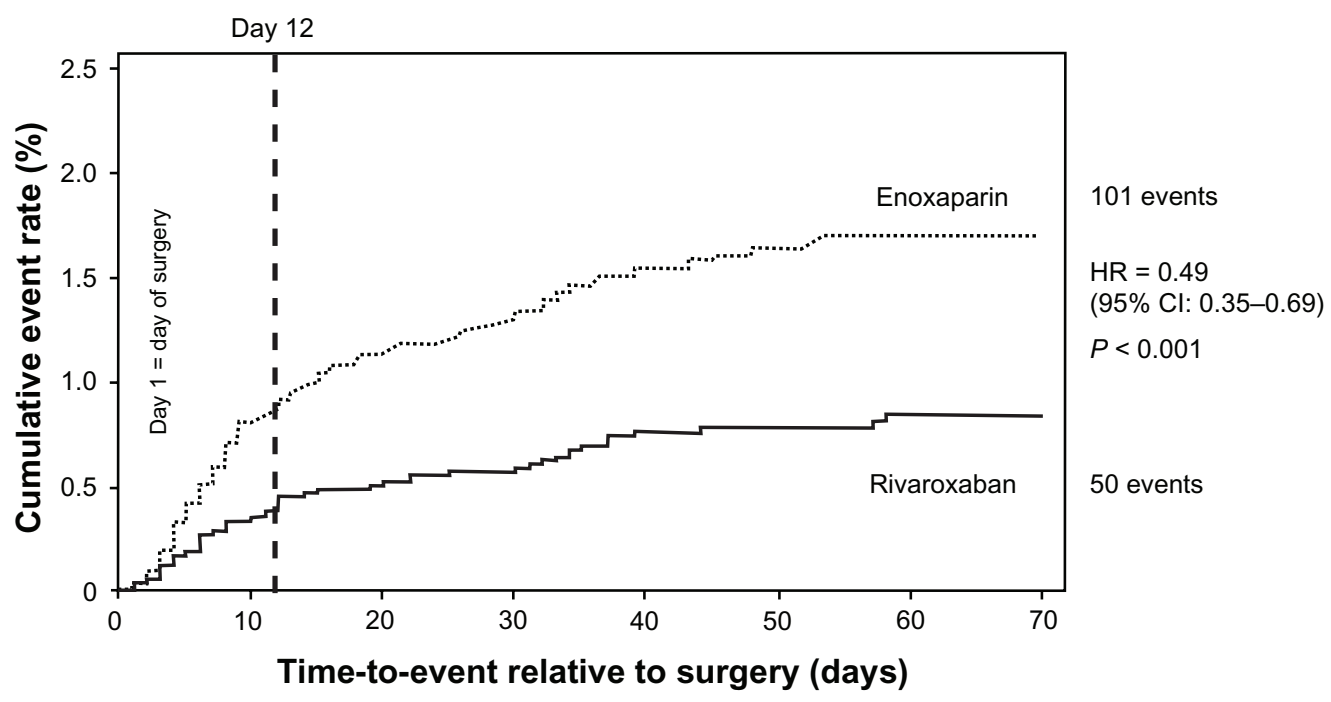

Figure I Symptomatic venous thromboembolism and all-cause mortality (during treatment and follow-up).

Notes: Safety population, $n=12,383$; subjects at risk, rivaroxaban $n=6200$ and enoxaparin $n=6183$.

Reprinted from Vasc Health Risk Manag, Vol 7, Kwong LM, Therapeutic potential of rivaroxaban in the prevention of venous thromboembolism following hip and knee replacement surgery, pages 46I-466, Copyright (C) 20I I, with permission from Dove Medical Press. ${ }^{36}$

Abbreviations: $\mathrm{Cl}$, confidence interval; $\mathrm{HR}$, hazard ratio.

clinical venous thromboembolism and mortality in patients undergoing total hip or knee arthroplasty.

\section{Disclosure}

LMK has received research grants from Astellas, Bayer, GlaxoSmithKline, Pfizer, sanofi-aventis, and Takeda. He is a consultant for Zimmer and also receives royalties for product development.

\section{References}

1. Falck-YtterY, Francis CW, Johanson NA, et al. Prevention of VTE in orthopedic surgery patients: Antithrombotic Therapy and Prevention of Thrombosis, 9th ed: American College of Chest Physicians Evidence-Based Clinical Practice Guidelines. Chest. 2012;141(Suppl 2):e278S-e325S.

2. Anderson FA, Ayers D, Colwell CW, et al. Bleeding concerns drive practices of orthopedic surgeons in prevention of venous thromboembolism in primary hip and knee arthroplasty. Presented at the International Society on Thrombosis and Haemostasis Annual Meeting, Boston, MA; July 11-16, 2009.

3. Friedman RJ, Gallus AS, Cushner FD, Fitzgerald G, Anderson FA Jr. Physician compliance with guidelines for deep-vein thrombosis prevention in total hip and knee arthroplasty. Curr Med Res Opin. 2008; 24(1):87-97.

4. Anderson FA Jr, Huang W, Friedman RJ, Kwong LM, Lieberman JR, Pellegrini VD Jr. Orthopaedic Surgeon's Survey Steering Committee. Prevention of venous thromboembolism after hip or knee arthroplasty: findings from a 2008 survey of US orthopedic surgeons. J Arthroplasty. 2012;27:659-666. e5.

5. Guyatt GH, Akl EA, Crowther M, Gutterman DD, Schuünemann HJ; American College of Chest Physicians Antithrombotic Therapy and Prevention of Thrombosis Panel. Executive Summary: Antithrombotic Therapy and Prevention of Thrombosis, 9th ed: American College of Chest Physicians Evidence-Based Clinical Practice Guidelines. Chest. 2012;141 Suppl 2:7S-47S.

6. Johanson NA, Lachiewicz PF, Leiberman JR, et al; AAOS Physician Volunteer Work Group. American Academy of Orthopaedic Surgeons clinical guideline on prevention of symptomatic pulmonary embolism in patients undergoing total hip or knee arthroplasty: summary of recommendations. J Am Acad Orthop Surg. 2009;17:183-196.
7. Colwell CW Jr, Collis DK, Paulson R, et al. Comparison of enoxaparin and warfarin for the prevention of venous thromboembolic disease after total hip arthroplasty. Evaluation during hospitalization and three months after discharge. J Bone Joint Surg Am. 1999;81:932-940.

8. Leclerc JR, Geerts WH, Desjardins L, et al. Prevention of venous thromboembolism after knee arthroplasty. A randomized, double-blind trial comparing enoxaparin with warfarin. Ann Intern Med. 1996;124: 619-626.

9. Hull R, Raskob G, Pineo G, et al. A comparison of subcutaneous lowmolecular-weight heparin with warfarin sodium for prophylaxis against deep-vein thrombosis after hip or knee implantation. $N$ Engl $J$ Med. 1993;329:1370-1376.

10. Kwong LM, Kistler KD, Mills R, Wildgoose P, Klaskala W. Thromboprophylaxis, bleeding and post-operative prosthetic joint infection in total hip and knee arthroplasty: a comprehensive literature review. Expert Opin Pharmacother. 2012;13:333-344.

11. Turpie AG, Bauer KA, Eriksson BI, Lassen MR. Fondaparinux vs enoxaparin for prevention of venous thromboembolism in major orthopaedic surgery: a meta-analysis of 4 randomized double-blind studies. Arch Intern Med. 2002;162:1833-1840.

12. Rosenkranz B, Fischer C, Meese CO, Frölich JC. Effects of salicylic and acetylsalicylic acid alone and in combination on platelet aggregation and prostanoid synthesis in man. Br J Clin Pharmacol. 1986;21:309-317.

13. Lotke PA, Lonner JH. The benefit of aspirin chemoprophylaxis for thromboembolism after total knee arthroplasty. Clin Orthop. 2006;452: $175-180$.

14. Orthopedics today. DVT thromboprophylaxis: What is your treatment choice? Available from: http://www.healio.com/.../DVT-prophylaxisWhat-is-your-treatment-choice. Accessed July 30, 2010.

15. Madhusudhan TR, Rangan A, Gregg PJ. Gastric protection and gastrointestinal bleeding with aspirin thromboprophylaxis in hip and knee joint replacements. Ann R Coll Surg Engl. 2008;90:332-335.

16. Pulmonary Embolism Prevention (PEP) Trial Collaborative Group. Prevention of pulmonary embolism and deep vein thrombosis with low dose aspirin: Pulmonary Embolism Prevention (PEP) trial. Lancet. 2000;355:1295-1302.

17. Ginsberg JS, Davidson BL, Comp PC, et al; RE-MOBILIZE Writing Committee. Oral thrombin inhibitor dabigatran etexilate vs North American enoxaparin regimen for prevention of venous thromboembolism after knee arthroplasty surgery. $J$ Arthroplasty. 2009;24:1-9. 
18. Eriksson BI, Dahl OE, Rosencher N, et al. Dabigatran etexilate versus enoxaparin for prevention of venous thromboembolism after total hip replacement: a randomised, double-blind, non-inferiority trial. Lancet. 2007;370:946-956.

19. Eriksson BI, Dahl OE, Büller HR, et al. A new oral direct thrombin inhibitor, dabigatran etexilate, compared with enoxaparin for prevention of thromboembolic events following total hip or knee replacement: the BISTRO II randomized trial. J Thromb Haemost. 2005;3:103-111.

20. Lassen MR, Raskob GE, Gallus A, Pineo G, Chen D, Hornick P; ADVANCE-2 investigators. Apixaban versus enoxaparin for thromboprophylaxis after knee replacement (ADVANCE-2): a randomised double-blind trial. Lancet. 2010;375:807-815.

21. Lassen MR, Gallus A, Raskob GE, et al. Apixaban versus enoxaparin for thromboprophylaxis after hip replacement. $N$ Engl J Med. 2010;363:2487-2498.

22. Lassen MR, Davidson BL, Gallus A, Pineo G, Ansell J, Deitchman D. The efficacy and safety of apixaban, an oral, direct factor Xa inhibitor, as thromboprophylaxis in patients following total knee replacement. J Thromb Haemost. 2007;5:2368-2375.

23. Perzborn E, Kubitza D, Misselwitz F. Rivaroxaban. A novel, oral, direct factor $\mathrm{Xa}$ inhibitor in clinical development for the prevention and treatment of thromboembolic disorders. Hamostaseologie. 2007;27: 282-289.

24. Eriksson BI, Borris LC, Friedman RJ, et al. Rivaroxaban versus enoxaparin for thromboprophylaxis after hip arthroplasty. $N$ Engl J Med. 2008;358:2765-2775

25. Kakkar AK, Brenner B, Dahl OE, et al. Extended duration rivaroxaban versus short-term enoxaparin for the prevention of venous thromboembolism after total hip arthroplasty: a double-blind, randomised controlled trial. Lancet. 2008;372:31-39.

26. Lassen MR, Ageno W, Borris LC, et al. Rivaroxaban versus enoxaparin for thromboprophylaxis after total knee arthroplasty. $N$ Engl J Med. 2008;358:2776-2786.

27. Turpie AG, Lassen MR, Davidson BL, et al. Rivaroxaban Versus Enoxaparin for Thromboprophylaxis After Total Knee Arthroplasty (RECORD4): a randomised trial. Lancet. 2009;373:1673-1680.
28. Lassen MR, Gent M, KakkarAK, Eriksson BI, Homering M, Berkowitz SD, Turpie AG. The effects of rivaroxaban on the complications of surgery after total hip or knee replacement: results from the RECORD programme. J Bone Joint Surg Br. 2012 Nov;94(11):1573-8.

29. Trkulja V, Kolundzic R. Rivaroxaban vs dabigatran for thromboprophylaxis after joint-replacement surgery: exploratory indirect comparison based on meta-analysis of pivotal clinical trials. Croat Med J. 2010;51:113-123.

30. Gómez-Outes A, Terleira-Fernández AI, Suárez-Gea ML, VargasCastrillón E. Dabigatran, rivaroxaban, or apixaban versus enoxaparin for thromboprophylaxis after total hip or knee replacement: systematic review, meta-analysis, and indirect treatment comparisons. $B M J$. 2012;344:e3675.

31. Cohen A, Drost P, Marchant N, et al. The efficacy and safety of pharmacological prophylaxis of venous thromboembolism following elective knee or hip replacement: systematic review and network meta-analysis. Clin Appl Thromb Hemost. 2012;18:611-627.

32. Turpie AG, Lassen MR, Eriksson BI, et al. Rivaroxaban for the prevention of venous thromboembolism after hip or knee arthroplasty. Pooled analysis of four studies. Thromb Haemost. 2011;105:444-453.

33. Lassen MR, Turpie AG, Kakkar AK, Eriksson BI, Gent M. Potential impact of rivaroxaban on surgical safety outcomes after total hip or knee replacement surgery. Presented at the 53rd Annual Meeting of the International Society on Thrombosis and Haemostasis, Vienna, Austria; February 3-7, 2009.

34. Dahl OE, Quinlan DJ, Bergqvist D, Eikelboom JW. A critical appraisal of bleeding events reported in venous thromboembolism prevention trials of patients undergoing hip and knee arthroplasty. J Thromb Haemost. 2010;8:1966-1975.

35. Anderson FA, Huang Y, Friedman RJ, Kwong LM, Lieberman JV, Pelligrini VD. Prevention of venous thromboembolism following hip or knee arthroplasty: findings from a 2008 survey of US orthopaedic surgeons. J Arthroplasty. 2012;27:659-666

36. Kwong LM. Therapeutic potential of rivaroxaban in the prevention of venous thromboembolism following hip and knee replacement surgery. Vasc Health Risk Manag. 2011;7:461-466.
Clinical Pharmacology: Advances and Applications

\section{Publish your work in this journal}

Clinical Pharmacology: Advances and Applications is an international, peer-reviewed, open access journal publishing original research, reports, reviews and commentaries on all areas of drug experience in humans. The manuscript management system is completely online and includes a very quick and fair peer-review system, which is all easy to use.

\section{Dovepress}

Visit http://www.dovepress.com/testimonials.php to read real quotes from published authors. 